University of Rhode Island

DigitalCommons@URI

Open Access Master's Theses

1980

\title{
DEVELOPMENT OF A MAMMALIAN COLLAGENASE ASSAY USING A SOLUBLE SUBSTRATE
}

Nancy A. LaPosta-Frazier

University of Rhode Island

Follow this and additional works at: https://digitalcommons.uri.edu/theses

\section{Recommended Citation}

LaPosta-Frazier, Nancy A., "DEVELOPMENT OF A MAMMALIAN COLLAGENASE ASSAY USING A SOLUBLE SUBSTRATE" (1980). Open Access Master's Theses. Paper 201.

https://digitalcommons.uri.edu/theses/201

This Thesis is brought to you for free and open access by DigitalCommons@URI. It has been accepted for inclusion in Open Access Master's Theses by an authorized administrator of DigitalCommons@URI. For more information, please contact digitalcommons-group@uri.edu. 


\author{
DEVELOPMENT OF A MAMMALIAN \\ COLLAGENASE ASSAY USING \\ A SOLUBLE SUBSTRATE \\ by
}

NANCY A. LAPOSTA-FRAZIER

A THESIS SUBMITTED IN PARTIAL FULFILLMENT OF THE

REQUIREMENTS FOR THE DEGREE OF

MASTER OF SCIENCE

IN

PHARMACOLOGY AND TOXICOLOGY

UNIVERSITY OF RHODE ISLAND

1980 


\section{MASTER OF SCIENCE THESIS \\ $\mathrm{OF}$}

NANCY A. LAPOSTA-FRAZIER

Approved:

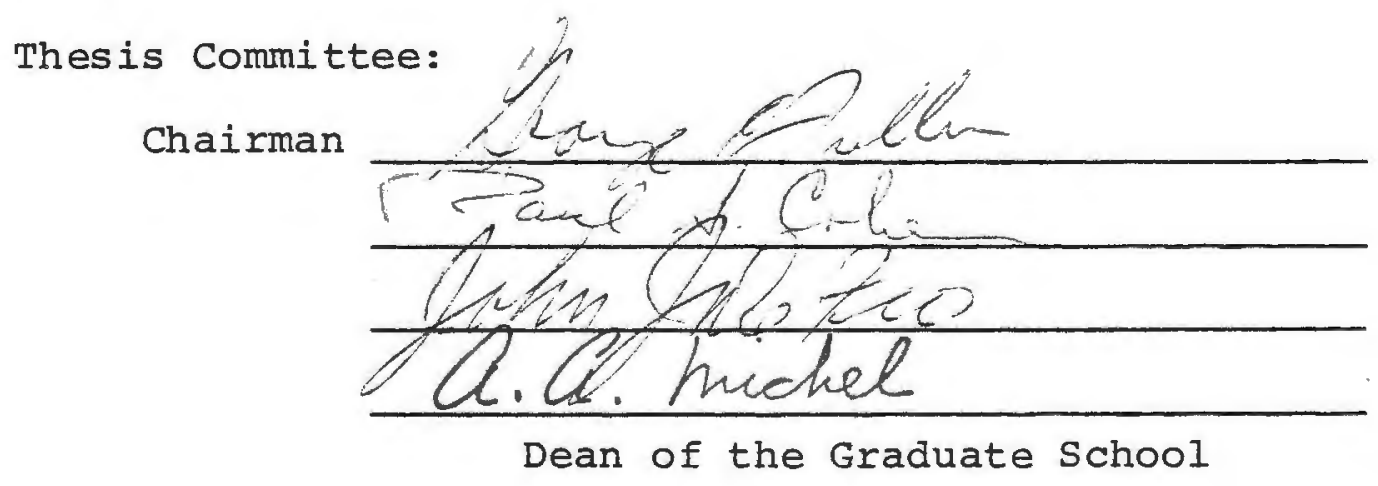

UNIVERSITY OF RHODE ISLAND

1980 


\section{ABSTRACT}

LaPosta-Frazier, Nancy A. M.S., University of Phode Island, 1980. Development of a Mammalian Collagenase Assay Using a Soluble Substrate. Major Professor: Dr. George C. Fuller.

The classical assay for detection of collagenolytic activity has been the release of soluble peptide fragments from reconstituted radioactive gels following incubation with the enzyme. Because this assay system is dependent on diffusion of the enzyme through the gel, examination of the kinetic parameters of the enzyme has been hampered. In the present study, a soluble substrate for collagenase was developed by coupling purified Type I collagen to the fluorophor, 2-methoxy-2,4-diphenyl-3(2H) furanone (MDPF).

MDPF-labeled collagen was incubated with varying amounts of collagenase for two hours and electrophoresed on polyacrylamide gels. The gels were scanned on a Gilford spectrophotometer and the resulting peaks quantitated on a Neumonic Electronic planimeter. It was found that the relationship between substrate disappearance and product disappearance was not stoichiometrical. After treatment of the fluorophor-labeled substrate with pepsin, the formation of product and breakdown of substrate was stoichiometrical. 
To test the integrity of the triple-helix, MDPF-labeled Type 1 collagen was treated with trypsin. The results indicate that substrate treated with pepsin was more resistant to trypsin degradation than fluorescent collagen not pretreated with pepsin. 


\section{ACKNOWLEDGEMENTS}

I wish to thank Dr. George C. Fuller not only for his patience and guidance, but more importantly, for showing me how to think and reason scientifically.

Special thanks to Ronald Goldberg for the preparation of the Type I collagen and to Dr. Paul S. Cohen for the preparation of the ${ }^{14}$ C-tryptophan-labeled E. coli protein.

Iastly I wish to thank my husband, Michael, for putting up with grinders and cold pizzas so that this thesis could be written. 
TABLE OF CONTENTS

PAGE

ABSTRACT. . . . . . . . . . . . . .

ACKNOWLEDGEMENTS. . . . . . . . . . . . iv

TABLE OF CONTENTS . . . . . . . . . . . . . V v

LIST OF TABLES. . . . . . . . . . . . . v vi

LIST OF FIGURES . . . . . . . . . . . . . vii v vi

INTRODUCTION. . . . . . . . . . . . . . 1

LITERATURE SURVEY . . . . . . . . . . . 3

Collagen Heterogeneity . . . . . . . 3

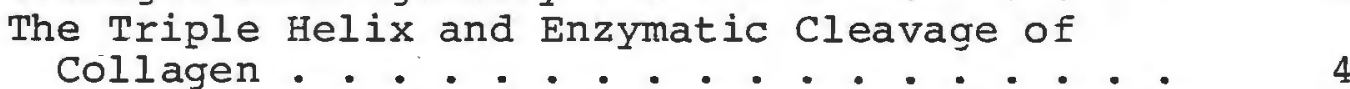

Physical Characteristics of Collagenase. . . 6

Assays for Determination of Collagenase
Activity . . . . . . . . . . 8

EXPERIMENTAL. . . . . . . . . . . . . . 12

Materials. . . . . . . . . . . . 12

Selection of Protease Inhibitors . . . . . 12

Preparation of Purified Collagen . . . . . . 13

The Labeling of the Collagen Substrate. . . . 14

The Collagenase Reaction Mixture . . . . . . 16

Electrophoresis and Quantitation of Gels . . . 16

Statistical Methods............. 17

RESULTS . . . . . . . . . . . . . . 18

DISCUSSION. . . . . . . . . . . . . 22

BIBLIOGRAPHY. . . . . . . . . . 42 


\section{IIST OF TABLES}

TABLE

PAGE

I Collagenase Cleavage Values for Group 1 non-pepsinized MDPF-labeled Type I collagen. . . . . . . . . . . . .

II Collagenase Cleavage Value for Group I Pepsinized MDPF-labeled Type I Collagen.

II Effect of Trypsin on MDPF-labeled

Collagen (Group 1) Before and After

Pepsin Treatment. . . . . . . . . . .

IV Collagenase Cleavage Values for Group 2 non-pepsinized MDPF-labeled Type 1 Collagen. . . . . . . . . . . . .

V Collagenase Cleavage Values for Group 2 Pepsinized MDPF-labeled Type 1 Collagen .

VI Effect of Trypsin on MDPF-labeled Collagen (Group 2) Before and After Pepsin Treatment. . . . . . . . . . 
1 SDS-Acrylamide Electrophoresis of MDPFlabeled Type 1 Collagen. . . . . . . . . 33

2 SDS-Acrylamide Electrophoresis of MDPFlabeled Type 1 Collagen After the Collagenase Reaction . . . . . . . . .

3 Comparison of Fluorescent Intensity of MDPF-labeled Type 1 Collagen Before and After Treatment with Pepsin. . . . . . .

4 The Relationship Between Cleavage of Pepsinized MDPF-labeled Type 1 Collagen and Formation of $\mathrm{TC}_{\mathrm{A}}$ and $\mathrm{TC}_{\mathrm{B}}$ during the Collagense Reaction (Group 1). . . . . . .

5 The Relationship Between Cleavage of Pepsinized MDPF-labeled Type 1 Collagen and Formation of $\mathrm{TC}_{\mathrm{A}}$ and $\mathrm{TC}_{\mathrm{B}}$ During the Collagense Reaction (Group 2 ) 


\section{INTRODUCTION}

The tertiary structure of the collagen molecule is unique, consisting of three polypeptide chains rich in rigid glycine-proline peptide bonds and assembled as a righthanded triple helix. This conformation renders the protein resistant to nonspecific proteolytic attack; degradation occurs only as a result of enzymatic cleavage by either a bacterial or vertebrate collagenase.

Collagenase has been implicated in the etiology of connective tissue disorders characterized by excessive collagen degradation, such as rheumatoid arthritis, corneal ulceration, peridontal disease, and tumor invasion. Less clear is the role collagenase may play in the collagen disorders resulting from collagen accumulation. Researchers have traditionally concentrated their efforts on parameters of increased production (Grant and Prockop, 1972); however, recently several workers have proposed that increased collagen deposition may result from an interplay of increased synthesis and decreased degradation (Perez-Tomayo, 1978).

Defining the role of vertebrate collagenase in these collagen accumulation diseases has been hampered by lack of a sensitive, convenient assay which quantitates vertebrate collagenase. The classical assay for detection of vertebrate collagenase consists of applying a tissue sample or extract 
suspected of containing enzyme on a radiolabeled collagen gel and subsequently, counting solubilized peptides (Gross and Lapiere, 1962; Gross and Nagai, 1965). Problems with this assay procedure include lengthy preparation times, low specific activity of substrate and dependence on the rate of diffusion of the enzyme through the gel. Newer assay procedures have attempted to deal with these problems but a sensitive assay has yet to become the standard in the field. It is the purpose of this present study to attempt to develop such an assay for vertebrate collagenase utilizing a purified substrate coupled to the fluorophor, 2-methoxy-2, 4-dipheny1-3-(2N) furanone (MDPF). Essentially, the procedure consists of incubating human skin collagenase with the fluorescent-labeled substrate followed by quantitation of the reaction products as isolated on polyacrylamide gels. 
LITERATURE SURVEY

Collagen Heterogeneity

Collagen, the major fibrous protein constituent of connective tissue, (Kivirikko and Risteli, 1976), exists as a right-handed triple helical molecule, consisting of intertwined alpha chains. There are seven genetically distinct $\alpha$-chains. Each $\alpha$-chain is composed of approximately 1000 amino acid residues with an average molecular weight of 95000 daltons (Kivirikko and Risteli, 1976). At present, five types of collagen have been described, differing both in their amino acid composition, degree of hydroxylation and glycosylation, as well as their biological location. Type I collagen, found in bone, skin, tendon and dentin is composed of two identical $[\alpha 1(I)]$ chains and one $\alpha 2$-chain which differs in its primary amino acid sequence. It is the most prevalent collagen type. Type II collagen, located only in cartilage, is composed of three $\alpha_{1}$ (II) chains. A higher ratio of hydroxylysine to lysine residues and more glycosidally bound carbohydrate (Harris and McCroskery, 1974) distinguishes Type II from Type I collagen. Type III collagen which consists of an $\alpha 1$ (III) trimer, is abuncant in fetal tissue, and is found in muscle, aorta and skin. It can be separated from Type I collagen by differential salt precipitation following pepsin digestion (Chung and Miller, 1974; Epstein, 1974) 
and differs from Type I in containing more 4-hydroxyproline and cysteine residues. The latter form disulfide bonds within the helical portion of the molecule. Basement membrane collagen, or Type IV, contains high amounts of hydroxylated amino acids and cysteine residues. Type IV collagen has a higher molecular weight than the other collagen types attributable to a $12.5 \%$ hexose content (Kefalides, 1971).

Type $V$ or $A B$ collagen, has recently been described in the literature. Type $\mathrm{V}$ collagen, unlike other collagens, has three distinct molecular formulas: $[\alpha A]_{3},[\alpha B]_{3}$, and $\alpha A[B]_{2}$ and is thought to be found in placenta, lung, all muscle tissues, calvaria and cartilage (Minor, 1980). In its amino acid composition, Type $V$ collagen is similar to Type IV, in that it contains a significant number of both 3-hydroxyproline residues and glycosylated hydroxylysines (Burgeson et al., 1976).

The Triple Helix and Enzymatic Cleavage of Collagen

One of the crucial steps in collagen biosynthesis is the association of $\alpha$-chains into the triple helix. The formation and strength of the helix is dependent on both the disulfide bonds found in the $\mathrm{N}$-terminal peptide extensions of the molecule (Kivirikko and Risteli, 1976) as well as to the hydroxylation of proline residues with subsequent synthesis of water bridges (Minor, 1980). The tightness of the triple helix is attributable to the presence of glycine as every third residue in the primary amino acid sequence. 
Because of its unique helical conformation, native collagen is resistant to nonspecific protease attack; however, it is susceptible to cleavage by two types of collagenases, each possessing a distinct specificity for the collagen molecule. Bacterial collagenase (EC 3.4.24.3), commonly isolated from Clostridium histolyticum, cleaves the molecule at primary and secondary sites (Seifter and Harper, 1970). The most common point of attack occurs in the center of a four residue sequence consisting of Proline-Y-Glycine-Proline. The secondary sites of cleavage are numerous and appear to occur in four residue sequences where the second amino acid is usually hydroxyproline and the third residue is always glycine (Weiss, 1976).

Vertebrate and mammalian collagenases attack the collagen molecule at one specific locus between residues 772-773. This cleavage site corresponds to the peptide bond between glycine and leucine in the $\alpha l$ (I) chain and to the amino acids glycine and iso-leucine in the $\alpha 2$ chain (Gross et al., 1974). The two peptide products formed in the reaction comprise $75 \%$ and $25 \%$ of the original molecule and are called $\mathrm{TC}_{\mathrm{A}}$ and $\mathrm{TC}_{\mathrm{B}}$, respectively (Gross and Nagai, 1965).

Although fibrillar collagen possesses a denaturation temperature in excess of $55^{\circ} \mathrm{C}$, collagen in solution denatures at $37^{\circ} \mathrm{C}$. In contrast to these, $\mathrm{TC}_{\mathrm{A}}$ has a denaturation temperature $\left(\mathrm{T}_{\mathrm{m}}\right)$ of $32 \mathrm{C}$, while $\mathrm{TC}_{\mathrm{B}}$ has a $\mathrm{T}_{\mathrm{m}}$ of $29^{\circ} \mathrm{C}$. At physiological temperatures, then, the helical products would quickly denature and become susceptible to nonspecific protease attack. 
Early pioneers in the field (Sakai and Gross, 1967) hypothesized that collagenase was responsible for the further degradation of the cleavage products; however, later evidence indicates that this is not so. McCroskery et al. (1973) provided visual proof on polyacrylamide gels that collagenase cleaves native collagen into two characteristic products only. Furthermore, the enzyme is unable to cleave denatured collagen, that is, gelatins, under assay conditions identical to those in which the enzyme is active against soluble helical collagen (McCroskery et al., 1973). Instead, gelatin is cleaved by specific peptide hydrolases to dialyzable fragments (Weiss, 1976).

Physical Characteristics of Collagenase

The molecular weight of collagenase varies between 31000 and 60000 daltons depending on the source of the enzyme. Pulmonary alveolar macrophage collagenase has a reported molecular weight of 31000 (Horwitz et al., 1976), while human and bovine fibroblasts produce collagenases of molecular weights of 40000 and 60000 , respectively (Bauer et al., 1975; Birkedal-Hansen et al., 1976).

Collagenase requires calcium as a cofactor and is inhibited by whole serum, $\alpha_{2}$-macroglobulin and metal chelators, such as EDTA and 1,10 phenanthroline (Birkedal-Hansen et al..' 1976). Early reports indicated that human skin collagenase was inhibited by $\alpha_{I^{-}}$anti-trypsin (Eisen et al., 1971); 
however, subsequent data (Birkedal-Hansen et al., 1976) suggest that the antiprotease is inactive against the enzyme. It is quite possible that the antiprotease used by Eisen was contaminated with a 40000 molecular weight protein which elutes after $\alpha_{1}$-antitrypsin on Sephadex G-200 (Woolley et al., 1975).

Collagenase has been isolated in a precursor form but whether the latent enzyme exists as a zymogen or as an enzymeinhibitor complex has been the subject of debate. Early work (Eisen et al., 1971) indicated that a lag period of 24 to 48 hours occurred before the appearance of active collagenase in media of explants of human skin; however, immunoreactive enzyme was detected within the first six hours. The authors hypothesized that the initial lack of enzyme activity was attributable to inhibition by serum anti-proteases. They did not consider the possibility of latent enzyme.

The question of whether collagenase existed as a proenzyme was further investigated in 1976. In that year, BirkedalHansen et al. (1976) isolated a collagenase zymogen from human fibroblasts which did not bind to $\alpha_{2}$-macroglobulin. Upon activation with trypsin and loss of an 18000 molecular weight peptide, the enzyme reacted with the antiprotease. It should be noted that the human fibroblast enzyme was not unique in its susceptibility to trypsin activation: a collagenase isolated from human leukocytes was activated by both trypsin and rheumatoid synovial fluids. The proenzyme was released as a result of phagocytosis of aggregated 
$\gamma$-globulin by neutrophils (Oronsky et al., 1973).

In summary, the enzyme can be physiologically inhibited in two ways: initially, it is synthesized as an inactive precursor, but upon activation, can still be inhibited by serum proteins such as $\alpha_{2}$ macroglobulin.

\section{Assays for the Detection of Collagenase Activity}

The classical assay for the detection of collagenase activity has been the release of soluble peptide fragments from reconstituted radioactive gels following incubation with the enzyme (Gross and Lapiere, 1962). In these earliest experiments, explants of amphibian tail fins were utilized as the source of enzyme. In subsequent assays (Gross and Nagzi, 1965; Nagai et al., 1966; Sakai and Gross, 1967) enzyme purified by ammonium sulfate precipitation and Sephadex gel filtration was used. In addition to the solubilization of the radioactive gels, earliest researchers capitalized on two physiochemical properties of collagen: its viscosity and high negative optical rotation. Upon incubation with collagenase (Gross and Nagai, 1965), collagen in solution undergoes a drop in viscosity without any change in optical rotation. The authors interpreted this to mean that collagenase cleaved the collagen molecule without changing the triple helical nature of the substrate or products. Since this experiment was conducted at $20^{\circ} \mathrm{C}$, well below the denaturation temperature of collagen, $\mathrm{TC}_{\mathrm{A}}$ or $\mathrm{TC}_{\mathrm{B}}$ their early interpretation has 
proved correct. Visualization of the products of the reaction was made on polyacrylamide gels and by segment long spacing (SLS) electron microscope (Gross and Nagai, 1965). Although the gel lysis method was a milestone in collagenase research, there are drawbacks to its utilization on a wide scale. First, the labeled procedure for collagen as outlined by Gross, calls for the injection of the radioactive ịsotope, ${ }^{14} \mathrm{C}$-glycine, into guinea pigs and subsequent extraction and purification of the collagen. This results in a substrate with low specific activity. Secondly, the actual preparation of the gels is time-consuming: collagen in solution must be incubated for twelve hours at $37^{\circ}$ after which, the gels must be disrupted with a steel needle and reincubated an additional hour (Nagai et al., 1966). In addition, the assay suffers from high background and a sensitivity which varies depending on $\mathrm{pH}$, ionic strength and ionic species present in test samples (Terato et al., 1976). Lastly, results of the assay are highly dependent on rate of diffusion of the enzyme through the gel preventing kinetic analysis of the enzyme. As a result, many investigators have sought to develop new assay systems which would prove easier and more sensitive to use.

One of the first modifications of Gross's assay system involved the formation of collagen gels after incubation with the enzyme (Sakamoto et al., 1972). Essentially, ${ }^{3} \mathrm{H}-$ soluble collagen was incubated with varying amounts of collagen at $25 \mathrm{C}$. After stopping the reaction with EDTA, the 
components were incubated at $37^{\circ} \mathrm{C}$ to a llow for fibril formation. Subsequently, reaction products were separated from. undigested collagen and counted. Again, this assay system suffered from lack of sensitivity attributable to the low specific activity of the in vivo labeled collagen. The authors themselves indicated that significantly longer reaction and gel incubation times are needed to detect nonpurified enzyme.

Other researchers have sought to increase sensitivity by labeling purified collagen. The labeling procedures include a reduction reaction of collagen and $\mathrm{NaB}^{3} \mathrm{H}_{4}$ (Hu et al., 1978), production of free radicals in evacuated quartz tubes and subsequent reaction with ${ }^{3} \mathrm{H}_{2} \mathrm{~S}$ (Labrosse et al..' 1976) and acetylation reactions of acid soluble collagen and $\left(1-{ }^{14} \mathrm{C}\right.$ ) acetic anhydride (Gisslow and McBridge, 1975). In all cases, the labeled collagen produced was higher in specific activity; however, other problems still persisted. In the collagenase reactions of both Labrosse et al. (1976) and Gisslow and McBride. (1975), phosphotungstic acid (PTA) is used to precipitate undigested substrate; however, PTA may also precipitate the cleavage products of mammalian collagenase. To circumvent this problem, Labrosse suggests using the traditional preformed gels of Nagai, but this would essentially defeat the time-saving aspects of these alternative systems. Although $\mathrm{Hu}$ 's procedure does appear to be quite sensitive, problems are evident with his 
methodology. In testing his substrate for susceptibility to nonspecific protease attack, $24^{\circ} \mathrm{C}$ was selected as the incubation temperature, instead of the $37^{\circ} \mathrm{C}$ used in those experiments designed to prove the increased sensitivity of this system.

Other current assays for collagenase include a film microassay procedure (Levenson, 1976) and dioxane extraction of in vivo labeled reaction products (Terato et al., 1976). Again, the latter method suffers from low specific activity of the collagen substrate. Likewise, data was not presented concerning the substrate's resistance to nonspecific protease attack.

Recently, Goldberg and Fuller (1978) described a method for quantitating denatured collagen in solution. In their system, purified collagen $\alpha_{1}$-chains were coupled to the fluorophor, 2-methoxy-2,4-diphenyl-3-(2H)-furanone (MDPF) and quantitated after separation by electrophoresis in polyacrylamide gels. One of the distinct advantages to MDPF is that the molecule itself is not fluorescent, but becomes so only after coupling to primary amines. Any MDPF that remains unreacted is subsequently hydrolyzed (Weigle et al., 1973). This current study proposes to quantitate the separated products of the collagenase reaction by using MDPFlabeled collagen as the substrate. 
EXPERIMENTAL

\section{Materials}

The MDPF and human skin collagenase used in these experiments were gifts from Hoffman-LaRoche Laboratories, Nutley, New Jersey. All chemicals used in the Neville gel system were of electrophoretic grade quality (Eastman). All other chemicals used were analytical reagent grade.

\section{Selection of Protease Inhibitors}

The purity of the human skin collagenase was tested by incubating the enzyme with ${ }^{14} \mathrm{C}$-tryptophan labeled $\underline{E}$ - coli protein. For this reaction, $1 \times 10^{-2} \mathrm{ml}$ of collagenase was incubated at $37^{\circ} \mathrm{C}$ for three hours with $0.2 \mathrm{ml}$ of the labeled E. coli protein. The specific activity of the E. Coli protein utilized was $35,000 \mathrm{cpm} / \mathrm{ml}$ minute. The reaction was terminated by addition of $0.1 \mathrm{ml}$ of $50 \%$ trichloroacetic acid (TCA). TO aid protein precipitation, $0.1 \mathrm{ml}$ of a $1 \%$ bovine serum albumin (BSA) solution was added as a co-precipitant and the tubes refrigerated at $4^{\circ} \mathrm{C}$ overnight. The following day, the tubes were centrifuged for 15 minutes at $5000 \mathrm{rpm}$. The supernatant was removed and precipitated again with the BSA. For the second precipitation, the sample was kept at $4^{\circ} \mathrm{C}$ for thirty minutes. The tubes were then centrifuged 
for 15 minutes at $5000 \mathrm{rpm}$ and an aliquot of the supernatant was counted in a liquid scintillation counter.

To decrease the percent of nonspecific proteolysis of the crude collagenase solution, various protease inhibitors were added to the reaction mixture. To optimize conditions, N-ethylmaleimide (NEM) was added in concentrations ranging from $6.25 \times 10^{-4} \mathrm{M}$ to $6.25 \times 10^{-3} \mathrm{M}$, E-amino-n-caproic acid ( $E A C A)$ from $1.25 \times 10^{-2}$ to $3.75 \times 10^{-1} M$ and phenylmethylsulfonyl fluoride (PMSF) from $3.5 \times 10^{-5}$ to $8.75 \times 10^{-5} \mathrm{M}$. The reactions were carried out as described above.

Preparation of Purified Collagen

Type I collagen was purified according to the method of Fujui and Kuhn (1975). Salt soluble collagen was first extracted from calf skin with $0.05 \mathrm{M}$ Tris, pH 7.5, containing 1.OM sodium chloride. This was followed by extraction of acid soluble collagen in $10 \%$ acetic acid at $4^{\circ} \mathrm{C}$. The remaining insoluble material was lyophilized. To recover Type I collagen, the Iyophilized insoluble material was treated with pepsin. For this procedure, the crude collagen was rehydrated with $0.1 \%$ acetic acid to a concentration of $4.0 \mathrm{mg} / \mathrm{ml}$. Pepsin was added twice to the suspension and stirred for two 24-hour periods. For the first extraction, pepsin was added to a final concentration of $100 \mathrm{ug} / \mathrm{ml}$; for the second period the concentration was $70 \mathrm{ug} / \mathrm{ml}$. 
The resulting supernatant was filtered at $4^{\circ} \mathrm{C}$ and solid sodium chloride added to a final concentration of $0.9 \mathrm{M}$. The collagen was then harvested by centrifugation at 15,000 x $\mathrm{g}$ for 1 hour and the resulting pellet resuspended in $0.05 \mathrm{M}$ Tris-HCl, $\mathrm{pH}$ 7.5. The buffered collagen solution was kept at $4^{\circ} \mathrm{C}$ for four days to inactivate the pepsin and then centrifuged at $35000 \mathrm{x} g$ for 1 hour. The pelleted collagen was then lyophilized.

Type I collagen is biochemically separated from Type III collagen by differential salt precipitation. Iyophilized collagen was dissolved in $0.05 \mathrm{M}$ Tris containing $1.0 \mathrm{M} \mathrm{NaCl}$. The sodium chloride concentration was then adjusted to $1.7 \mathrm{M}$ and kept at $4^{\circ}$ for 24 hours to precipitate Type III collagen. The mixture was then centrifuged for 2 hours at $35000 \times \mathrm{g}$ and the NaCl concentration of the resulting supernate raised to $2.5 \mathrm{M}$ to precipitate the Type I collagen. After a 24 hour settling period, the collagen solution was centrifuged at $35000 \times \mathrm{g}$ for 2 hours and the resulting pellet suspended in 1\% acetic acid. After exhaustive dialysis against $1 \%$ acetic acid, the solution was centrifuged for 1 hour at $55,000 \mathrm{x} \mathrm{g}$ and the resulting supernant lyophilized.

The Labeling of the Collagen substrate

The Iyophilized Type I collagen was dissolved in 1.0mM acetic acid by stirring overnight at $4^{\circ} \mathrm{C}$. The $\mathrm{pH}$ of the collagen solution was raised to 10 by addition of $2 \mathrm{~N}$ sodium 
hydroxide to a final concentration of $2 \%(\mathrm{v} / \mathrm{V})$. The MDPF, dissolved at a concentration of $2 \mathrm{mg} / \mathrm{ml}$ in acetone, was added to the collagen solution in a $20 \%(\mathrm{v} / \mathrm{v})$ ratio. The $\mathrm{pH}$ of the coupled collagen was then returned to neutrality with a 0.02 volume of $2 \mathrm{~N}$ hydrochloric acid.

After completion of the labeling reaction, the fluorescent substrate was exhaustively dialyzed against deionized distilled water and then stored at $4^{\circ} \mathrm{C}$; however, any collagen molecules which would denature in the labeling process would not pass through the dialysis tubing and would remain with the labeled substrate. Since denatured collagen is susceptible to nonspecific protease attack, the presence of these a-chains in the reaction mixture would result in a disappearance of substrate which would not be accounted for in the appearance of product. In an attempt to circumvent this problem, MDPF-labeled collagen was treated with pepsin.

For this procedure, $5.0 \mathrm{mg}$ of labeled collagen was dissolved in $4.0 \mathrm{ml}$ of $1 \mathrm{mM}$ acetic acid and treated with MDPF as outlined above. 10.0 ug of pepsin, equivalent to 25 units, was added and the $\mathrm{pH}$ lowered by addition of $2.5 \mathrm{ml}$ of $1.0 \mathrm{~N}$ acetic acid. The collagen solution was dialyzed overnight against $1.0 \mathrm{~N}$ acetic acid at $4{ }^{\circ} \mathrm{C}$ and then dialyzed exhaustively against deionized distilled water to inactivate the pepsin. To quantitate the amount of collagen remaining in the solution, aliquots of the dialyzate were compared to a standard curve constructed of nondialyzed MDPF-labeled collagen. 
The Collagenase Reaction Mixture

The enzymatic reaction to test the appropriateness of MDPF-collagen as a substrate for mammalian collagenase consisted of a buffered collagen solution, protease inhibitors, cofactors, and enzyme. Specifically, 50.0 ug of labeled collagen dissolved in deionized distilled water, was buffered in $0.05 \mathrm{M}$ Tris-HCL, $\mathrm{pH} 7.5$ containing $5.0 \mathrm{mM}$ calcium chloride as an enzyme cofactor. NEM, $\varepsilon-A C A$ and PMSF were added to the reaction as protease inhibitors. The final concentrations of these inhibitors were $1.8 \times 10^{-1} \mathrm{M}$ for $\varepsilon \mathrm{ACA}, 6.5 \times 10^{-5}$, for PMSF and $1.0 \times 10^{-4}$ for NEM. Finally, $5.0 \times 10^{-4}$ to $3.0 \times 10^{-3} \mathrm{ml}$ of human skin collagenase was added to the mixture which was then incubated at $27^{\circ} \mathrm{C}$ in a constant temperature water bath for two hours. The reaction was terminated by addition of $2.5 \times 10^{-2} \mathrm{ml}$ of a $20 \%$ sucrose, $8 \mathrm{M}$ urea solution and $1.0 \times 10^{-2} \mathrm{ml}$ of a $10 \%$ sodium dodecyl sulfate (SDS) solution. To denature the collagen further, the tubes then were heated for thirty minutes at $56^{\circ} \mathrm{C}$. The standard curve for fluorescent collagen was constructed by using the above assay procedure in the absence of enzyme.

\section{Electrophoresis and Quantitation of Gels}

The collagenase reaction samples were then electrophoresed according to the method of Neville (1971). The concept of the Neville gel system is based on a sodium dodecyl sulfate-protein complex electrophoresed in a discontinuous 
buffer. The gels utilized in this procedure were composed of a $6.9 \%$ acrylamide: bisacrylamide running gel overlayed with $0.1 \mathrm{ml}$ of a $3.2 \%$ acrylamide:bisacrylamide concentrating gel. $1.5 \times 10^{-5} \mathrm{~g}$ of collagen was placed on $5 \times 60 \mathrm{~mm}$ gels and electrophoresed for one hour at 0.1-0.2 mA per tube. The amperage was then raised to $1.5 \mathrm{~mA}$ per tube until completion of run.

After electrophoresis, each tube was immediately scanned at $2 \mathrm{~cm} / \mathrm{min}$ in a Gilford 250 spectrophotometer equipped with a Gilford 2520 gel scanner and a Gilford 2515 fluorescence gel attachment. The exaitation wavelength of the gel attachment is $390 \mathrm{~nm}$; the emission wavelength is $480 \mathrm{~nm}$. Peak profiles of each gel were recorded on a Corning 840 recorder at a chart speed of $4 \mathrm{~cm} / \mathrm{min}$. The area of the $\alpha_{1}$ and $\mathrm{TC}_{\mathrm{A}}$ peaks from each gel were quantitated using a Neumonic Electronic planimeter Model 210-117. The planimeter was calibrated to give readings in square centimeters.

\section{Statistical Methods}
a). Mean: $\quad x=\frac{1}{n} \quad x_{i}$
where $\mathrm{n}=$ sample size
$x_{i}=$ sum of values for each sample.
b) Standard deviation: $s^{2}=\frac{I}{n}\left(x_{i}-\bar{x}\right)^{2}$
c) Linear regression: $Y=b_{0}+b_{1} X$

$$
\text { where } \begin{aligned}
& b_{I}=\frac{(X-\bar{X})(Y-\bar{Y})}{(X-\bar{X})} \\
& b_{0}+Y-b_{I} X
\end{aligned}
$$




\section{RESULTS}

This study was conducted to develop a sensitive assay for the detection of vertebrate collagenase using a purified collagen substrate coupled to the fluorophor, MDPF. Initial electrophoresis on Neville gels of purified Type I collagen coupled to MDPF indicated that this substrate was free of contaminating proteins. As shown in Figure 1 , the $\gamma, \beta, \alpha 1$ and $\alpha_{2}$ peaks are well defined and background fluorescence is minimal.

The purity of the vertebrate collagenase used was tested by incubating the enzyme with ${ }^{14}$ c-tryptophan labelled E.coli protein. $25 \%$ of the labeled protein was hydrolyzed by the enzyme, indicating significant contamination of the collagenase by nonspecific proteases. Therefore, protease inhibitors were necessary to decrease nonspecific degradation of the labeled protein. The final concentration of protease inhibitors found to be necessary to minimize hydrolysis were $1.4 \times 10^{-1} \mathrm{M}$ for $\varepsilon$-amino-n-caproic acid, $8.6 \times 10^{-5} \mathrm{M}$ for N-ethylmaleimide and $4.75 \times 10^{-5} \mathrm{M}$ for phenylmethylsulfonylfluoride.

The reaction of collagen and its degradative enzyme, collagenase, produces specific cleavage products when these are isolated on polyacrylamide gels as shown in Figure 2. . The last peak on the right corresponds to $\mathrm{TC}_{\mathrm{A}^{\prime}}$, the three- 
quarter length reaction product of the collagenase reaction. The remaining one-quarter fragment of the collagen molecule, designated $\mathrm{TC}_{\mathrm{B}^{\prime}}$ could not be detected on the acrylamide gels used in this investigation. To compensate for this, the amount of $\mathrm{TC}_{\mathrm{A}}$ detected was multiplied by a correction factor, 1.33, in order to describe the amount of collagen cleaved. The results obtained when human skin collagenase was incubated with MDPF-labeled Type I çollagen are reported in Tables I through IV. The substrates utilized were prepared at different times but under identical coupling conditions. The appearance of product, calculated as micrograms of cleaved collagen, is linear with the amount of enzyme used for both groups of substrate ( $r$ values of 0.985 and 0.905 , respectively). The disappearance of substrate, measured in terms of ugs of uncleaved collagen present on the gels was not linear with increasing amounts of enzyme ( $r$ values of -0.848 and -0.77 , respectively). The relationship between substrate disappearance and product appearance was calculated and found not to be stoichiometrical.

Examination of the data indicated that more collagen was cleaved than could be accounted for in the appearance of product. To test the stability of the substrate, MDPFlabeled collagen was incubated with trypsin. This resulted in a significant hydrolysis of the fluorescent substrate (Tables III and VI). This could indicate the presence of denatured collagen molecules which unlike native collagen 
would be susceptible to nonspecific protease attack. To circumvent this problem, $25 \mathrm{U}$ of pepsin was added to aliquots of labeled collagen and the mixture dialyzed overnight against 1.ON acetic acid. After recovery of the pepsin resistant collagen, the percent hydrolysis by trypsin of the resulting substrate was reduced (Tables III and VI), although hydrolysis was still observed at $2 \times 10^{-4}$ ugs of enzyme and above. Pepsin treatment of fluorophor labeled collagen was not found to diminish fluorescent intensity (Figure 3). For this experiment, collagen was dissolved in $1 \mathrm{mM}$ acetic acid and coupled with MDPF. The substrate was then divided into two aliquots, one of which was dialyzed against deionized distilled water, the other against iN acetic acid after the addition of $25 \mathrm{U}$ of pepsin to the collagen. After overnight dialysis against $1.0 \mathrm{~N}$ acetic acid the collagen mixture was dialyzed exhaustively against deionized water. Both standard curves shown in Figure 3 were obtained by electrophoresing a known quantity of labeled collagen on Neville gels and quantitating the resulting bands. The slopes of these lines are nearly identical: 0.82 and 0.77 for the non-pepsinized and pepsinized substrates, respectively.

Pepsin treatment of labeled collagen results in a more sensitive substrate. In Tables II and $V$ which list collagenase cleavage values for pepsinized collagen, $r$ values obtained from linear regression analysis are all above \pm 0.9 for both substrate disappearance and product appearance. 
The correlation between uncleaved and cleaved collagen is also linear for both substrates as observed in Figures 4 and 5, indicating that the problem of nonspecific hydrolysis of the fluorescent substrate was somewhat resolved. 


\section{DISCUSSION}

In a recent review, Perez-Tomayo (1978) states that a complete assay for collagenase activity would include not only measurement of a change in a physiochemical or biological property of collagen but also identification of the specific products of enzymatic cleavage. Traditionally, this would require two separate techniques. The physiochemical aspect could be measured as changes in viscosity, optical rotation, melting temperature or as the release of radioactively labeled collagen peptides from insoluble fibrils (Hu et al., 1978; Labrosse et al., 1978; Gisslow and McBride, 1975). Identification of the specific cleavage products could be achieved by electrophoresis on polyacrylamide gels or through formation and detection of SLS crystallites. The quantitation and evaluation of the collagenase reaction by most of these procedures is time-consuming and tedious.

The technique developed in this study, to follow the collagenase reaction through the quantitation of cleavage products from a fluorescent labeled substrate, alleviates the need for a two-part assay system. Quantitation of the collagenase reaction can be made by direct scanning of polyacrylamide gels for fluorescence and subsequent area analysis of the resulting peaks. Visualization and identification of $\mathrm{TC}_{\mathrm{A}}$ and $\mathrm{TC}_{\mathrm{B}}$ on the gels can be made under ultraviolet light. 
This system was found to compare favorably with the degree of sensitivity reported for detecting vertebrate collagenases using other assay procedures (Hu et al., 1978; Terato et al., 1976; Labrosse et al., 1976). Moreover, MDPFlabeled collagen has an additional advantage. Since an aliquot of the reaction mixture is used for electrophoresis, both cleaved and intact collagen can be measured. Thus, collagen recoveries can be monitored in each experiment. Previously described systems can only detect the amount of collagen cleaved.

Quantitation of MDPF-labeled $\alpha_{1}$-chains is linear down to the 10 nanogram range with a precision of $\pm 6 \%$ (Goldberg and Fuller, 1978). In the present assay system, the lowest detectable amount of collagen was 250 nanograms. The discrepancy between these figures can be explained by examination of the starting materials. The $\alpha_{I}$-chains used by Goldberg and Fuller were purified on both carboxymethylcellulose and agarose columns. Since these $\alpha_{1}$-chains were completely denatured, all possible primary amine sites were available for fluorescent coupling. For the present study, valid conditions for the collagenase reaction require a nondenatured, helical substrate. Since collagen in the native state consists of a right-handed triple helix composed of $\alpha$-chains coiled in left-handed minor helices (Weiss, 1978), it is quote possible that all primary amine sites are not available for the coupling reaction. Thus, the fluorescent collagen used here would not possess the fluo- 
rescent intensity of denatured chains. To circumvent this problem, early work in this project centered on attempts to renature MDPF-labeled $\alpha_{1}$-chains. For this procedure, labeled chains were dialyzed exhaustively against deionized distilled water at $4^{\circ} \mathrm{C}$ for 96 hours (Trocz and Kuhn, 1969). At the end of this period, it was found that renaturation had not occurred. Therefore, the addition of MDPF apparently interferes with helix formation.

The collagenase detection assay described here could prove to be a useful technique in connective tissue research. As can be observed in Tables II and $V$, increasing amounts of collagenase result in a linear increase in $\mathrm{TC}_{\mathrm{A}}$ and a linear decrease in amount of remaining pepsinized Type I collagen. Analysis of paired data for each level of collagenase used in these studies reveals a stoichiometrical relationship between product formation and substrate catalysis.

A number of problems still exist with the use of this system on a widespread basis. Trypsin degradation values for pepsinized collagen are still above acceptable levels. Hydrolysis of less than $10 \%$ of control values have been used by other investigators to indicate that the collagen substrate is in a native state (Perez-Tomayo, 1978). As can be observed in the results section, values obtained were scattered but above $10 \%$ in most cases. It is interesting to note in Table III, that the percent hydrolysis of 
labeled collagen was constant through $2.0 \times 10^{-4}$ ugs of trypsin indicating that the problem of nonspecific degradation has been somewhat alleviated.

Certain advantages are evident in the use of a soluble substrate, such as MDPF-labeled collagen, to detect collagenase. Primarily, enzyme activity would not depend on diffusion as it does in the traditional methodologies involving radioactively labeled gels (Gross and Lapiere, 1962). Because of this, investigators can then manipulate enzyme/ substrate ratios for kinetic studies.

In conclusion, MDPF-labeled collagen may become a useful tool in detecting vertebrate collagenase. Product formation as well as substrate degradation can be monitored. In addition, fluorescent scanning of the gels would reveal any other unexpected degradative product. In this present work, partially purified human skin collagenase was utilized as enzyme. In future studies, it might prove valuable to test MDPF-labeled collagen against crude extracts suspected of containing mammalian collagenase. 
TABLE I. COLLAGENASE CLEAVAGE VALUES FOR GROUP I NONPEPSINIZED MDPF-LABELLED TYPE 1 COLIAAGEN

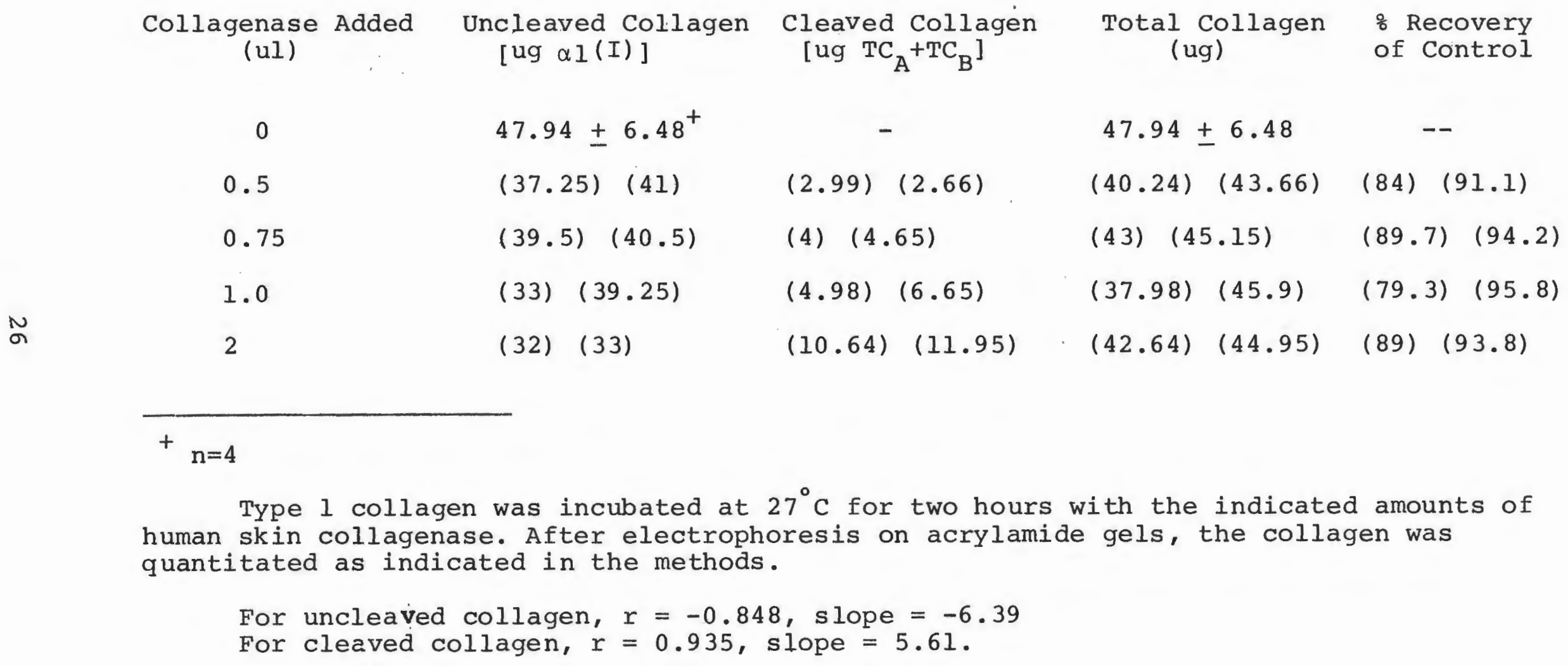


TABLE II. COLLAGENASE CLEAVAGE VALUES FOR GROUP 1 PEPSINIZED MDPF-IABELED TYPE 1 COLLAGEN

\begin{tabular}{|c|c|c|c|c|c|c|c|}
\hline $\begin{array}{c}\text { Collagense Added } \\
\text { (ul) }\end{array}$ & $\begin{array}{l}\text { Uncleaved Collagen } \\
{\left[\text { (ug } \alpha_{1}(I)\right]}\end{array}$ & $\begin{array}{l}\text { Cleaved } \\
\text { [ug } \mathrm{T}\end{array}$ & $\begin{array}{l}\text { Collagen } \\
{\left[\begin{array}{l}\left.\mathrm{TC}_{\mathrm{B}}\right]\end{array}\right.}\end{array}$ & $\begin{array}{r}\text { Total Col } \\
\text { (ug) }\end{array}$ & agen & $\begin{array}{l}\text { o Recover } \\
\text { of Contrc }\end{array}$ & \\
\hline 0 & $51.5 \pm 3.77^{*}$ & & - & $51.5 \pm$ & 3.77 & -- & \\
\hline 0.5 & $(45.5) \quad(42.5)$ & $(3.33)$ & $(1.65)$ & $(48.83)$ & $(44.15)$ & $(94.8)$ & $(85)$ \\
\hline 0.75 & $(44.5) \quad(42)$ & $(1.65)$ & $(4.3)$ & $(46.15)$ & $(46.3)$ & $(89.6)$ & $(90)$ \\
\hline 1 & $(39.25)$ & $(6.98)$ & $(8.0)$ & $(50.98)$ & $(47.25)$ & $(99) \quad(c$ & $91.7)$ \\
\hline 2 & $(31)$ & $(13.3)$ & $(14.3)$ & $(49.3)$ & $(45.3)$ & $(95.7)$ & $(88)$ \\
\hline 3 & $(29.5)$ & $(19.95)$ & $(18.6)$ & $(51.95)$ & $(48.1)$ & $(100.8)$ & $(95$. \\
\hline
\end{tabular}

\footnotetext{
$* \mathrm{n}=4$
}

Type 1 collagen, pepsinized as described in the methods, was incubated for 2 hours at $27^{\circ} \mathrm{C}$ with the indicated amounts of enzyme and quantitated as described in the methods.

For uncleaved collagen, $r=-0.934$, slope $=-6.32$

For cleaved collagen, $r=+0.98$, slope $=+6.89$ 

TABLE III. EFFECTS OF TRYPSIN ON MDPF-LABELLED COLLAGEN (GROUP 1 )
BEFORE AND AFTER PEPSIN TREATMENT

$\begin{gathered}\text { Trypsin Added } \\ \text { (ug) }\end{gathered}$
0
$1 \times 10^{-5}$
$5 \times 10^{-5}$
$1 \times 10^{-4}$
$2 \times 10^{-4}$
$5 \times 10^{-4}$

$\because$ Degradation of Non-pepsinized Type 1 Collagen

$\begin{array}{ll}(12) & (5.3) \\ (20.7) & (26.67) \\ (32.7) & (16 .) \\ (42.7) & (36.33) \\ (45.3) & (41.67)\end{array}$

$\because$ Degradation of Pepsinized Type 1 Collagen

$$
\begin{array}{ll}
(19) & (19.7) \\
(17.8) & (18.9) \\
(15.6) & (18.9) \\
(19) & (28.7) \\
(42.23) & (30.2)
\end{array}
$$

Type 1 collagen was incubated for 2 hours at $27^{\circ} \mathrm{C}$ with the indicated amounts of trypsin.

$+25 \mathrm{U}$ of pepsin was added to $5 \mathrm{mg}$ of Type 1 collagen and the solution analyzed overnight at $4 \mathrm{C}$ against $1.0 \mathrm{~N}$ acetic acid. 
TABLE IV. COLLAGENASE CLEAVAGE VALUES FOR GROUP 2 NON-PEPINIZED MDPF-LABELLED TYPE 1 COLLAGEN

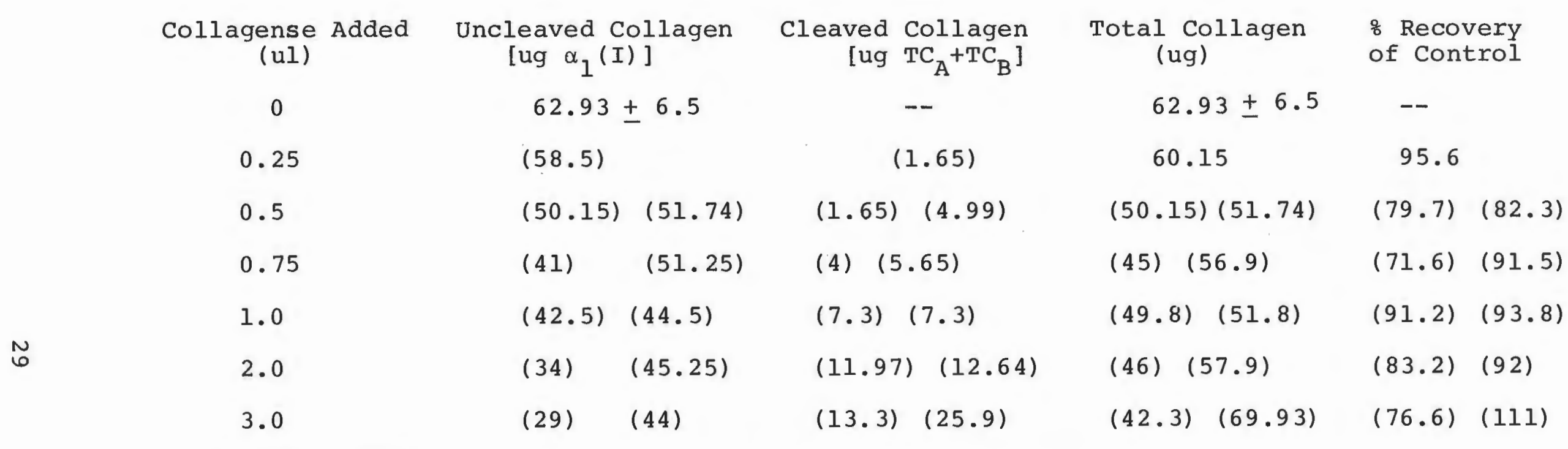

The indicated amounts of human skin collagenase were added to Type 1 collagen and incubated for 2 hours at $27^{\circ} \mathrm{C}$. Aliquots of the reaction products were run on $7{ }^{\circ}$ acryamide gels and quantitated.

For uncleaved collagen, $r=-77$, slope $=-7.15$

For cleaved collagen, $r=.905$, slope $=6.3$ 
TABLE V. COLLAGENASE CLEAVAGE VALUES FOR GROUP 2 PEPSINIZED MDPF-LABELLED TYPE I COLLAGEN

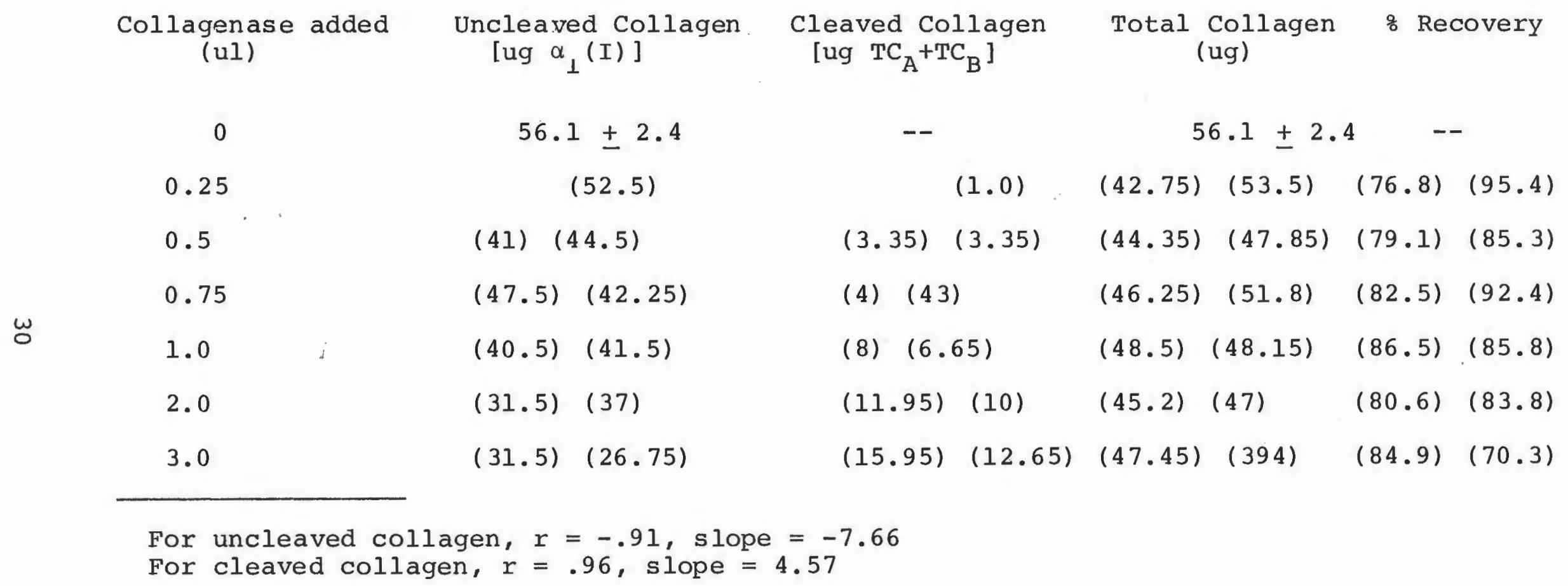


TABLE VI. EFFECT OF TRYPSIN ON MDPF-LABELED COLLAGEN (GROUP 2) BEFORE AND AFTER PEPSIN TREATMENT

\author{
Trypsin Added \\ (ug) \\ 0 \\ $1 \times 10^{-5}$ \\ $5 \times 10^{-5}$ \\ $1 \times 10^{-4}$ \\ $2 \times 10^{-4}$ \\ $5 \times 10^{-4}$
}

$\because$ Degradation of Non-pepsinized Type 1 Collagen

$\begin{array}{ll}(13.4) & (21.8) \\ (20.1) & (30) \\ (28.8) & (21.8) \\ (33) & (31.6) \\ (44) & (56)\end{array}$

(15.4) (8.4)

(15.42) (5.25)

(17.33) (4.6)

(25.6) (13.5)

(22.4) (36.4) 
Figure 1. SDS-Acrylamide Electrophoresis of MDPF-labeled Type I collagen. 15.0 ugs of fluorophorlabeled collagen was electrophoresed on Neville gels and scanned as described in the Methods. 


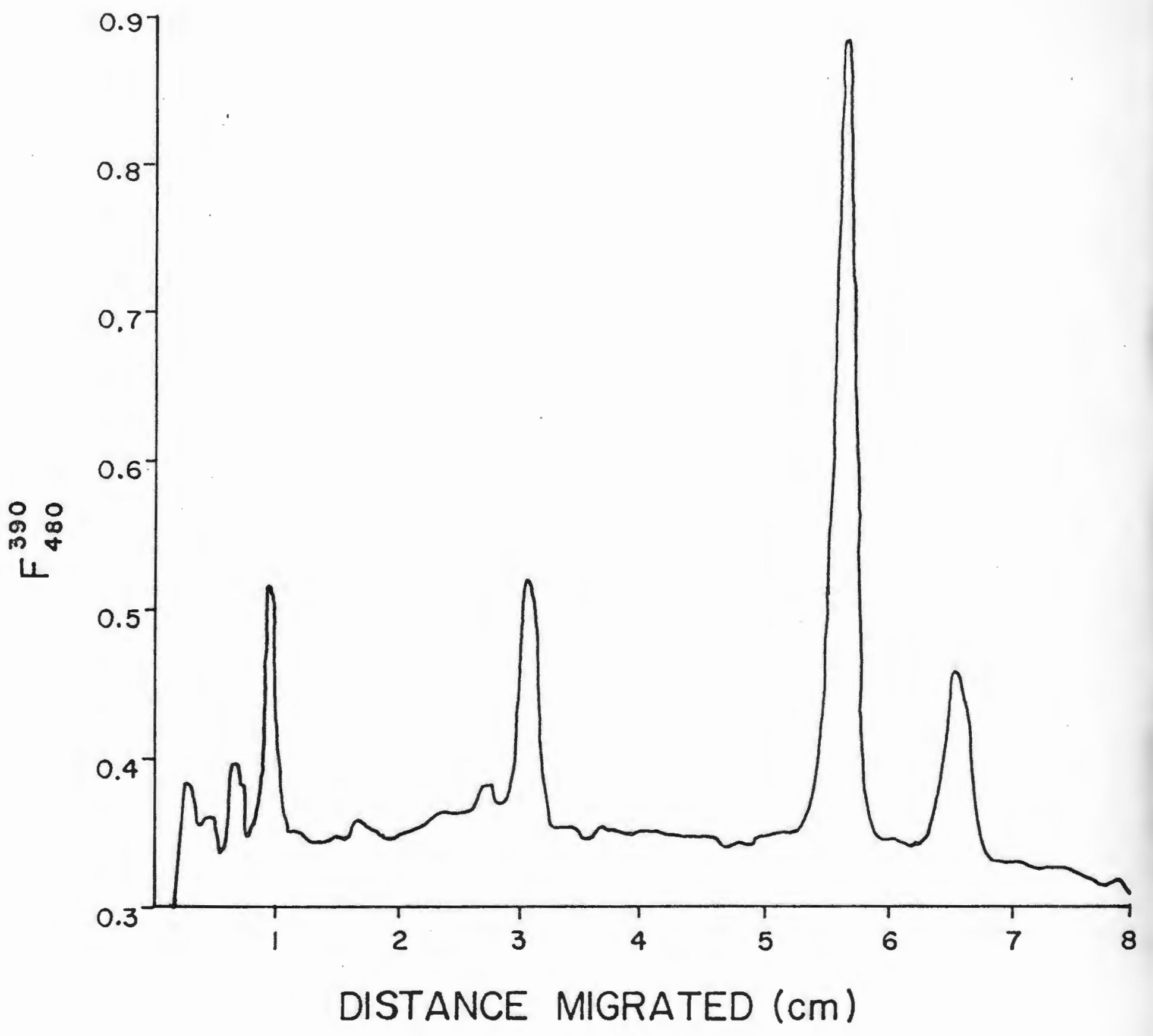


Figure 2. SDS-Acrylamide Electrophoresis of MDPF-labeled collagen after the collagenase reaction. 50.0 ugs of MDPF-labeled collagen was incubated with 2 ul of human skin collagenase for 90 minutes. 15.0 ugs of the labeled collagen was then electrophoresed on Neville gels and, afterwards, scanned as described in the Methods. 


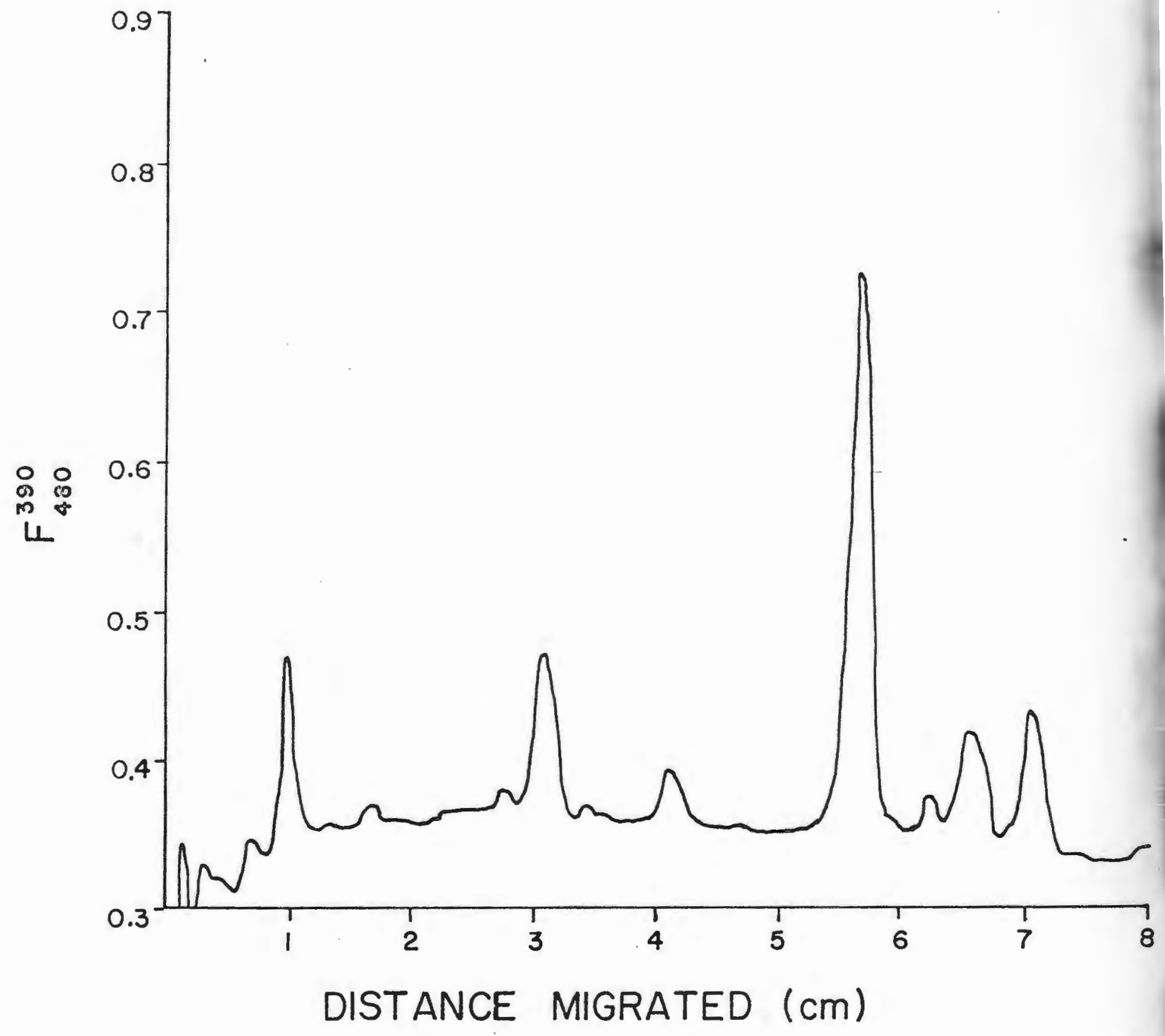


Figure 3. Comparison of fluorescent intensity of MDPFlabeled collagen before and after treatment with pepsin. 10.0 ugs of Type I collagen was dissolved in $8.0 \mathrm{mls}$ of $1 \mathrm{mM}$ acetic acid. After labeling with MDPF, aliquots were electrophoresed on Neville gels. $4.0 \mathrm{mls}$ of the original mixture ras then treated with $25 \mathrm{U}$ of pepsin as described in the Methods and electrophoresed. After scanning, both sets of gels were quantitated on a planimeter. 
Figure 4. The relationship between cleavage of pepsinized MDPF-labeled Type I collagen and formation of $\mathrm{TC}_{\mathrm{A}}$ and $\mathrm{TC}_{B}$ during the collagenase reaction (Group 1). 51.0 ugs of MDPF-labeled collagen was reacted with varying amounts of collagenase for two hours at $27^{\circ} \mathrm{C}$. Slope $=-0.82$, $r=-0.93$ 


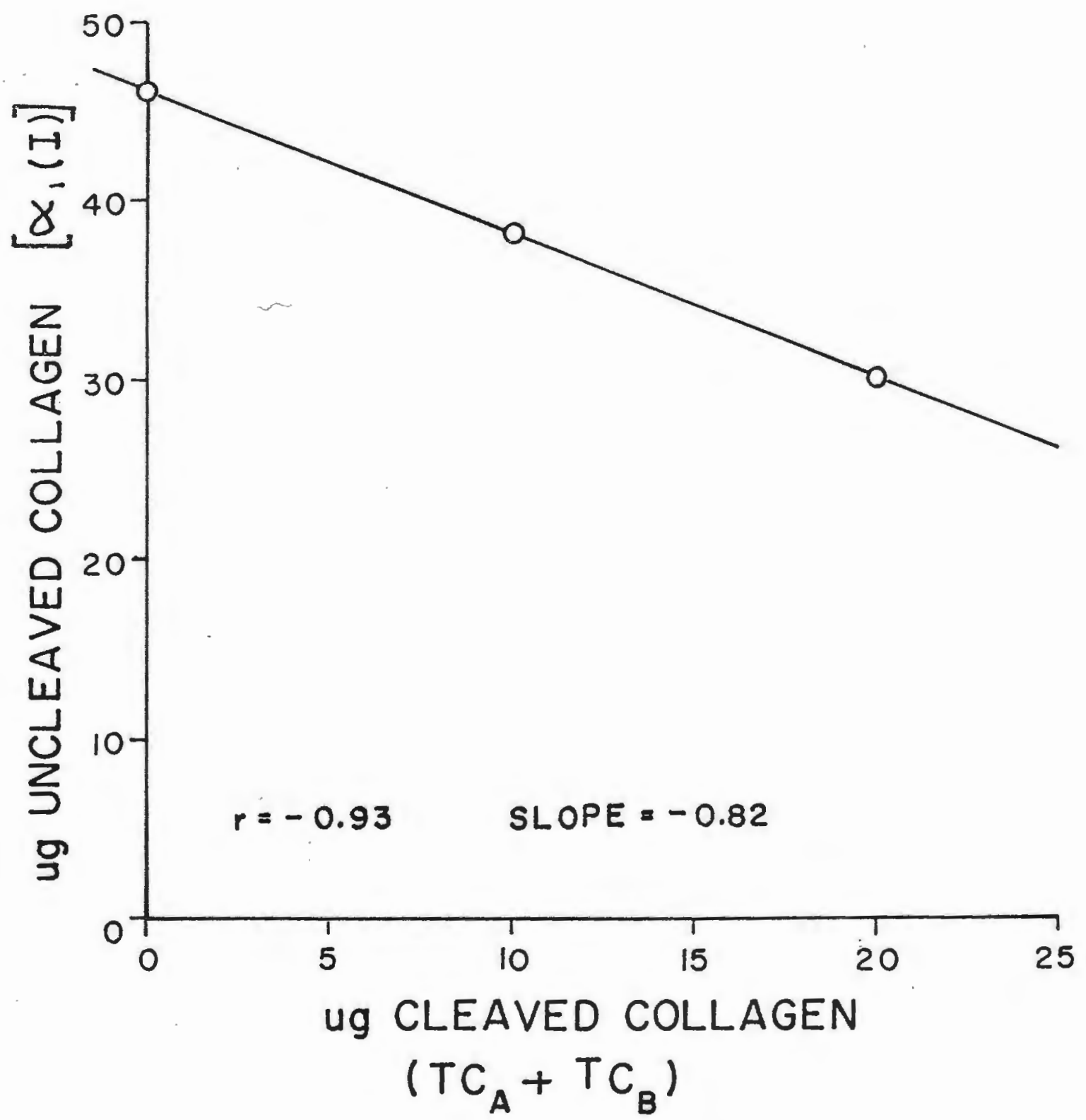


Figure 5. The relationship between cleavage of pepsinized MDPF-labeled Type I collagen and the formation of $\mathrm{TC}_{\mathrm{A}}$ and $\mathrm{TC}_{\mathrm{B}}$ during the collagenase reaction (Group 2). 56.0 ugs of MDPF-1abeled collagen was reacted with varying amounts of collagenase for two hours at $27^{\circ} \mathrm{C}$. Slope $=-1,45, r=-0.908$. 


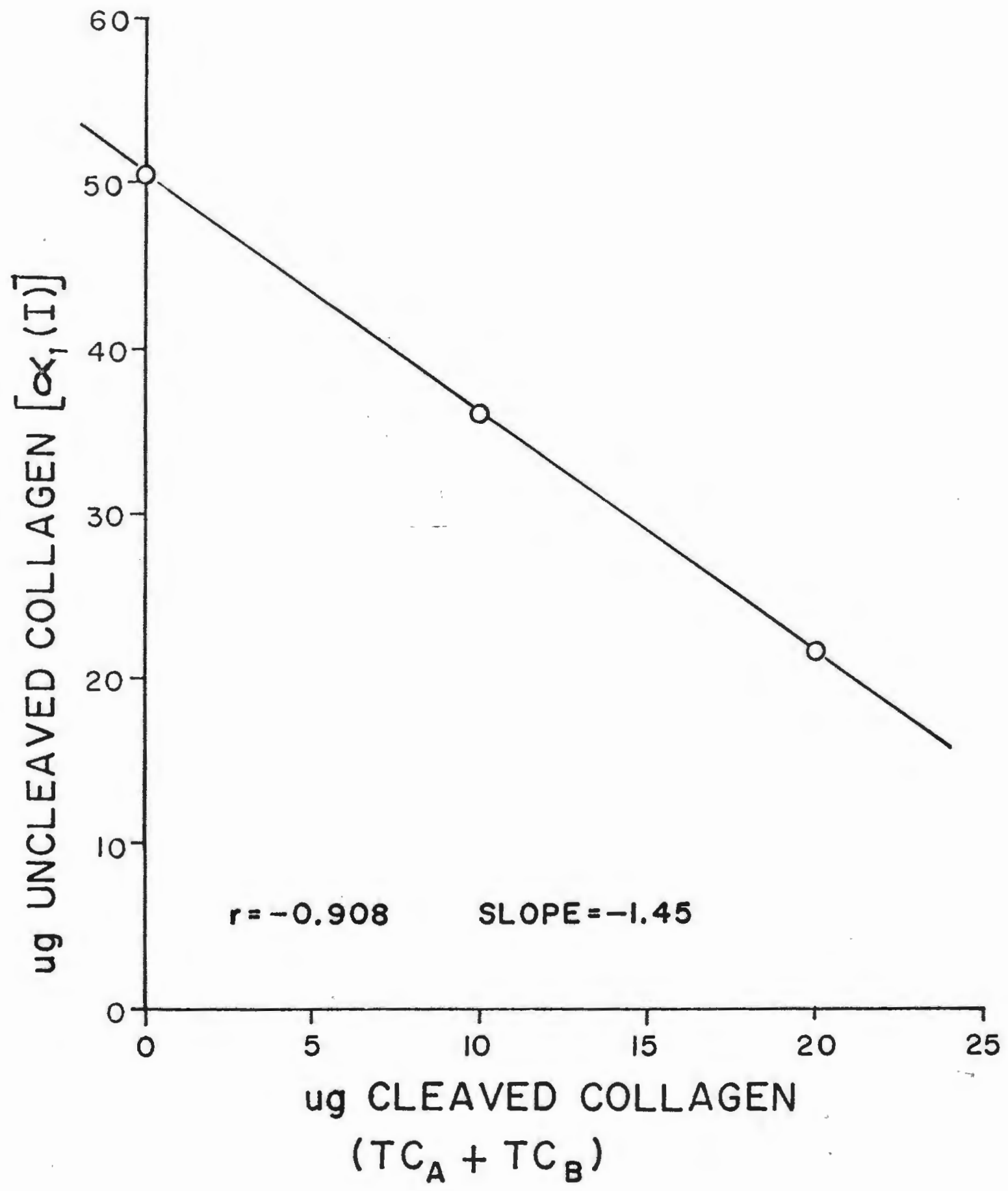




\section{REFERENCES}

Bauer, E.A., Stricklin, G.P., Jeffrey, J.J. and Eisen, A.Z.: Collagenase production by human skin fibroblasts. Biochem. Biophys. Res. Commun. 64: 232-240, 1975.

Burgeson, R.E., El Adli, F.A., Kaitila, I.I. and Hollister, D.W.: Fetal membrane collagens: Identification of two new collagen alpha chains. Proc. Natl. Acad. Sci. USA 73: 25792583,1976 .

Chung, E. and Miller, E.J.: Collagen polymorphism: Characterization of molecules with the chain composition 1(III) 3 in Human Tissues. Science 183: 1200-01, 1974.

Epstein, E.H. Jr.: $\left[\alpha_{I}\left(\right.\right.$ III $\left._{3}\right]$ Human skin collagen. Release by pepsin digestion and preponderance in fetal life. J. Biol. Chem. 2-19: 3225-31, 1974 .

Evanson, J.M., Jeffrey, J.J. and Krane, S.M.: Human collagenase: Identification and characterization of an enzyme from rheumatoid synovium in culture. Science 158: 499-502, 1967.

Fujui, T. and Kuhn, K.: Isolation and characterization of pepsin-treated Type III collagen from calf skin. HoppeSeyler's Z. Physiol. Chem. 356: 1793-1801, 1975.

Gisslow, M.T. and McBride, B.C.: A rapid sensitive collagenase assay. Anal. Biochem. 68: 70-78, 1975.

Goldberg, R. and Fuller, G.C.: Quantitation of collagen in polyacrylamide gels by fluorescent scanning of MDPF-labeled proteins: An improvement over densitometric scanning of gels stained by coomassie blue. Anal. Biochem. 90: 69-80, 1978 .

Grant, M.E., Prockop, D.J.: The bios-nthesis of collagen (in 3 parts). NEJM 286: 194-199, 242-249, 291-300, 1972 .

Gross, J., Harper, E., Harris Jr., E.D., McCroskery, F.A., Highsberger, John H., Corbett, C. and Kang, A.H.: Animal. collagenases: specificity of ocean and structures of the substrate cleavage site. Biochem. Biophy Res. Commun. 61: 605-612, 1974 . 
Gross, J. and Lapiere, C.M.: Collagenolytic activity in amphibian tissues: A tissue culture assay. Proc. Natl. Acad. Sci. USA 48: 1014-1022, 1962 .

Gross, J. and Nagai, Y.: Specific degradation of the collagen molecule by tadpole collagenalytic. Proc. Natl. Acad. Sci. USA 54: 1197-1206, 1965.

Harris, E.D. Jr. and McCroskery, F.A.: The influence of temperature and fibril stability on degradation of cartilage collagen by rheumatoid synovial collagenase. NEJM 290: 1-6, 1974 .

Horwitz, A.F. and Crystal, R.G.: Collagenase from rabbit pulmonary alveolar macrophages. Biochem. Biophys. Res. Commun. 69: 296-303, 1976.

Hu, C.L., Crombie, G. and Franzblau, C.: A new assay for collagenolytic activity. Anal. Biochem. 88: 638-643, 1978 .

Kefalides, M.A.: Isolation of a collagen from basement membranes containing three identical alpha chains. Biochem. Biophy. Res. Commun. 45: 226-234, 1971.

Kivirikko, K.I. and Risteli, G.: Biosynthesis of collagen and its alterations in pathological states. Medical Biol. $54: 159-86,1976$.

Labrosse, K., Liener, I. and Hargrave, P.A.: A sensitive assay for collagenolytic activity using initiated collagen. Anal. Biochem. 70: 218-223 (1976).

Levenson, R.: A collagen film microassay for tissue collagenase. Anal. Biochem. 76: 579-588, 1976.

McCroskery, F.A., Wood Jr., S. and Harris, E.D. Jr.: Gelatin: A poor substrate for a mammalian collagenase. Science 182: $70-71,1973$.

Minor, R.: Collagen metabolism. Amer. J. of Pathology 98: $226-77,1980$.

Nagai, Y., Lapiere, C.M. and Gross, J.: Tadpole collagenase. Preparation and purification. Biochem: 5: 3123-3130, 1966 .

Neville, D.M.: Molecular weight determination of protein dodecyl sulfate complex by gel electrophoresis in a discontinuous buffer system. J. Biol. Chem. 246: 6328-6334, 1971 .

Oronsky, A., Perper, R.J. and Scmoder, H.C.: Phagocytic release and activation of human leukocyte procollagenase. Nature 246: 417-19, 1973. 
Perez-Tomayo, R.: Pathology of collagen degradation. Am. J. Pathol. 92: 509-566, 1978 .

Sakai, T. and Gross, J.: Some properties of the products of reaction of tadpole collagenase with collagen. Biochem. 6 : $518-527,1967$.

Sakamoto, S., Goldhaber, P. and Geimaner, M.J.: A new method for the assay of tissue collagenase. Proc. Soc. Exp. Biol. Med. 139: 1057-1059.

Seifter, S., Harper, E.: Collagenases. Methods Enzymol. 19: $613-635,1970$.

Terato, T., Nagai, Y., Kawanishi, K. and Teramoto, S.: A rapid assay method of collagenase activity using labeled soluble collagen as substrate. Biochem. et Biophys Acta 445 : $753-762,1976$.

Tkocz, C. and Kuhn, K.: The formation of triple-helical collagen molecules from al or $\alpha 2$ polypeptide chains. Eur. J. Biochem. 7: 454-462, 1969.

Weigele, M., DeBernardo, I. and Reimgruber, W.: Fluorescent labeling of proteins. A new methodology. Biochem. Biophys. Res: Commun. 54: 899-906, 1973.

Weiss, J.B.: Enzymatic degradation of collagen. In Rev of Conn. Tiss. 7: 101-157, 1976.

Woolley, D.E., Roberts, D.R. and Evanson, J.M.: Inhibition of human collagenase activity by a small molecular weight serum protein. Biochem. Biophys Res. Commun. 66: 747-754, 1975. 